Research Article

\title{
Incidence of ear, nose and throat disorders in children: a study in a teaching hospital in Telangana
}

\section{Harika Surapaneni*, Shalini Singh Sisodia}

Department of ENT, Mallareddy Medical College for Women, Hyderabad, India

Received: 24 November 2015

Accepted: 05 December 2015

\author{
*Correspondence: \\ Dr. Harika Surapaneni, \\ E-mail: harikasneni@gmail.com
}

Copyright: (c) the author(s), publisher and licensee Medip Academy. This is an open-access article distributed under the terms of the Creative Commons Attribution Non-Commercial License, which permits unrestricted non-commercial use, distribution, and reproduction in any medium, provided the original work is properly cited.

\begin{abstract}
Background: ENT problems are very common among the children, especially diseases such as acute suppurative otitis media, acute tonsillitis, acute epiglottis, laryngotracheobronchitis, and rhinitis etc. Poor hygienic conditions, malnourishment, different socio-economic levels are also said to play a role in the prevalence of ENT disorders.

Methods: 417 children between the ages of 0-15, attending the ENT department in our hospital were included in the study. General demographic details such as age, sex, socio-economic status, clinical history, and examination for common ENT complaints and disorders was taken for all patients. Otoscopy for ear examination for diseases such as otitis media, ear perforation and ear discharge anterior rhinoscopy for nasal discharge, airway obstruction and infection were performed Presence of any adenoid hypertrophy was looked for. Throat examination was performed for any sign of tonsillitis or pharyngitis. Appropriate investigations such as X-rays, culture and sensitivity, etc were performed where necessary.

Results: 258 (61.9\%) patients were females while there were $159(38.1 \%)$ males. More than $45 \%$ cases who had disorders were concentrated in the 6-15 years age group. Almost $75 \%$ of the children were from lower socioeconomic status. Otitis media among the ear diseases, rhinitis in the nasal diseases and pharyngitis followed by tonsillitis in the diseases of the throat was found to be the most common.

Conclusions: Our study provides basic information of the prevalent disorders in ENT in our area, based on which we can take the relevant step towards development of the medical setup and treatment.
\end{abstract}

Keywords: Ear nose throat disorders, Children, Prevalence, Otitis media

\section{INTRODUCTION}

ENT problems are one of the most common causes that warrant a visit to the doctor, more so if the patient is a child. Paediatric population forms a considerable proportion of the total world's population. $35 \%$ of India's population, which is the world's second most populous country, are children.

Respiratory tract symptoms such as cough and cold, earache, sore throat, are very common in children especially when there is a climatic change or in the rainy and winter seasons. Many of the times, the treatment fir these are done at home itself or by using alternative treatment and symptomatic treatment, probably because of monetary reasons. When these symptoms become more serious, the children are normally brought to the doctor.

Ear, Nose, Throat problems are more common in children than in adults, especially diseases such as acute suppurative otitis media, Acute tonsillitis, acute epiglottis, laryngotracheobronchitis, and rhinitis etc. This could be due to various factors such as wider and horizontal Eustachian tube, under developed immunity, malnourishment, poor hygiene and sanitary conditions, owercrowding, lower socioeconomic status etc. ${ }^{2}$

Fortunately, fatality is very low in such cases except in cases of emergencies, but complications do occur inspite 
of improved health care facilities. ${ }^{3,4}$ Infection of the middle ear is reported to be one of the most common diseases in children due to altered Eustachian canal. ${ }^{6}$

Assessing the health related issues in children is considered to give an idea of the health status of a community..$^{5}$ This study was manly conducted to give us an idea of the prevalent disorders of the ear nose and throat in our area.

\section{METHODS}

This study was conducted in the Department of Ear, Nose and Throat at Mallareddy Medical College for women. 417 children between the ages of 0-15, attending the ENT department in our hospital were included in the study. Some of these children were referred to from the paediatric and medical department. General demographic details such as age, sex, socio-economic status were taken. Clinical history and examination for common ENT complaints and disorders was also taken for all patients.

Otoscopy for ear examination for diseases such as otitis media, ear perforation and ear discharge was done. In case of nasal examination, external, anterior rhinoscopy for nasal discharge, airway obstruction and infection were performed Presence of any adenoid hypertrophy was looked for.

Throat examination was performed for any sign of tonsillitis or pharyngitis. Appropriate investigations such as X-rays, culture and sensitivity, etc were performed where necessary.

Patients with expectorant, pneumonia, tuberculosis, hemoptysis and other diseases were excluded from the study. Children presenting with headache due to any ophthalmic reasons or neurological reasons were excluded from the study.

\section{RESULTS}

There was a predominance of females over males in our study. $258(61.9 \%)$ patients were females while there were $159(38.1 \%)$ (Figure 1).

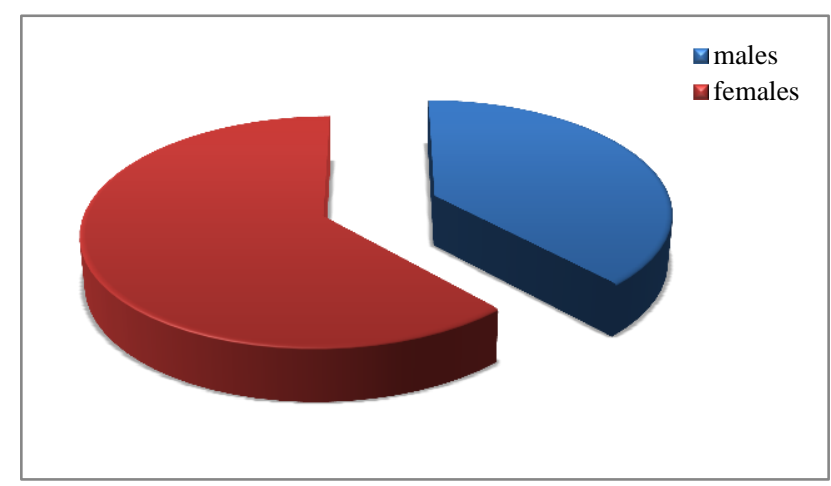

More number of disorders was concentrated in the 6-15 years age group, with more than $45 \%$ of the cases (Figure 2).

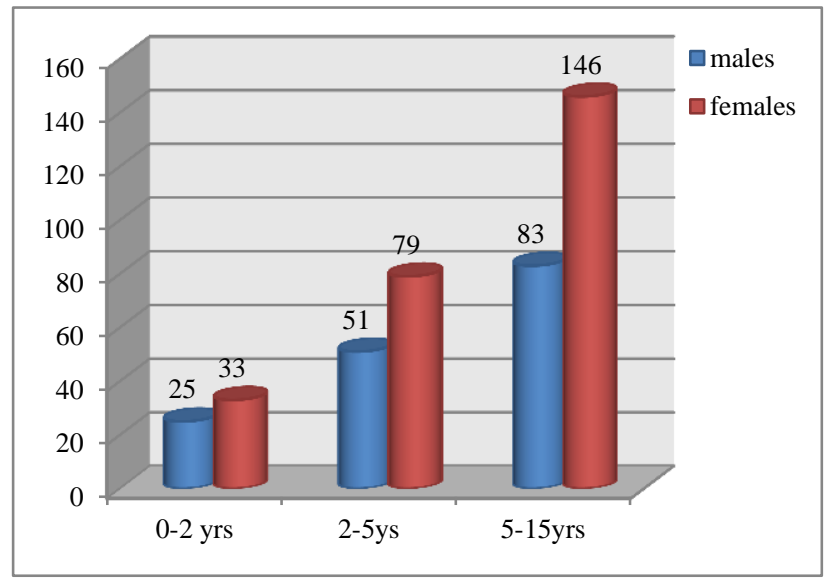

Figure 2: Age wise distribution of patients.

Almost $75 \%$ of the children were from lower socioeconomic status. Very few, around $8 \%$, were from upper class while the rest were from middle class. About $80 \%$ of these children were living in joint families (Figure 3).

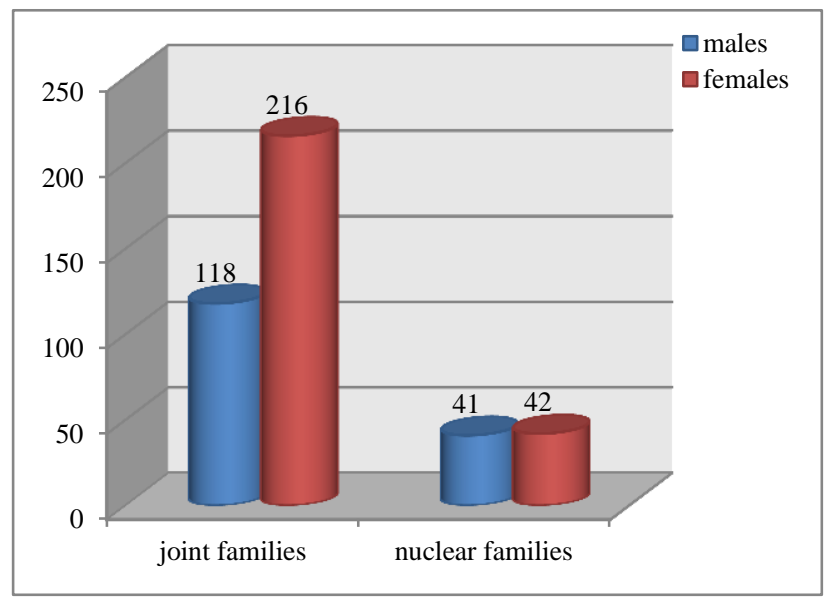

Figure 3: Style of living of the patients.

Among the 206 ear disorders, chronic suppurative otits media was the most common disorder accounting for $27.1 \%$ of the total cases and $54.9 \%$ of the ear disorders. Otits media with effusion accounted for $20 \%$ of the cases. There were very few cases of otomycosis which were $5.8 \%$ of the ear diseases. Rhinitis was the most common of the nasal disordes with $48.3 \%$ followed by chronic sinusitis $(17.2 \%)$. Infective rhinitis accounted for $12.5 \%$ of the nasal diseases. Pharyngitis $(38.2 \%)$ was the most common disorder of the throat followed by tonsillitis (33.3\%) (Table 1).

Figure 1: Sex wise distribution of patients. 
Table 1: Incidence of various ENT diseases.

\begin{tabular}{|c|c|c|c|}
\hline & Disorder & Number & $\begin{array}{l}\text { Percentage } \\
\text { (overall \%) }\end{array}$ \\
\hline \multirow{5}{*}{$\begin{array}{l}\text { Ear } \\
\text { disorders } \\
(n=206)\end{array}$} & $\begin{array}{l}\text { Chronic } \\
\text { suppurative } \\
\text { otitis media }\end{array}$ & 113 & $54.9 \%(27.1 \%)$ \\
\hline & $\begin{array}{l}\text { Otitis Media } \\
\text { with Effusion }\end{array}$ & 42 & $20.4 \%(10.1 \%)$ \\
\hline & Otomycosis & 12 & $5.8 \%(2.9 \%)$ \\
\hline & $\begin{array}{l}\text { Foreign body } \\
\text { ear }\end{array}$ & 8 & $3.9 \%(1.9 \%)$ \\
\hline & Ear Wax & 37 & $18 \%(8.9 \%)$ \\
\hline \multirow{9}{*}{$\begin{array}{l}\text { Nose } \\
\text { Disorders } \\
(n=377)\end{array}$} & Rhinitis & 182 & $48.3 \%(43.6 \%)$ \\
\hline & Allergic rhinitis & 47 & $12.5 \%(11.3 \%)$ \\
\hline & $\begin{array}{l}\text { Chronic } \\
\text { sinusitis }\end{array}$ & 65 & $17.2 \%(15.6 \%)$ \\
\hline & Epistaxis & 32 & $8.5 \%(7.7 \%)$ \\
\hline & Foreign body.3 & 19 & $5 \%(4.6 \%)$ \\
\hline & Nasal Polyp & 7 & $1.9 \%(1.7 \%)$ \\
\hline & $\begin{array}{l}\text { Deviation of } \\
\text { nasal Septum }\end{array}$ & 16 & $4.2 \%(3.8 \%)$ \\
\hline & Injuries & 4 & $1.1 \%(1 \%)$ \\
\hline & Others & 5 & $1.3 \%(1.2 \%)$ \\
\hline \multirow{6}{*}{$\begin{array}{l}\text { Throat } \\
\text { Disorders } \\
(n=348)\end{array}$} & Tonsillitis & 116 & $33.3 \%(28.7 \%)$ \\
\hline & Pharyngitis & 133 & $38.2 \%(31.9 \%)$ \\
\hline & $\begin{array}{l}\text { Cervical } \\
\text { lymphadenitis }\end{array}$ & 34 & $9.8 \%(8.2 \%)$ \\
\hline & $\begin{array}{l}\text { Adenoid } \\
\text { hypertrophy }\end{array}$ & 21 & $6 \%(5 \%)$ \\
\hline & Foreign body & 32 & $9.2 \%(7.7 \%)$ \\
\hline & Others & 12 & $3.5 \%(2.9 \%)$ \\
\hline
\end{tabular}

\section{DISCUSSION}

The main health problems in the paediatric population in India are low birth weight, malnutrition, infection and parotitis, poisoning, behavioural problems and accidents. ENT problems just add to these problems or may be a consequence of them. ${ }^{7}$

The predominant gender infected in our study was females compared to males although this distribution was not significant, though a similar distribution was found in another study by Yeli. ${ }^{8}$

In our study, the most common morbidity of the ear was due to Otitis media, both CSOM as well as that with effusion both together accounting for about $75 \%$ of the ear disorders. Impacted was seen in $18 \%$ of the ear disorders. Similar was the case in a study by Yeli $^{11}$ and by Kishve et al, ${ }^{9}$ although in a study by Nepali et al, the most common ear disorder was Ear Wax which accounted for over $40 \%$ of the cases. ${ }^{10}$ We had a low prevalence of otmycosis consisting of $5.8 \%$ of the ear disordes and $2.9 \%$ of overall ENT disorders. This was reported in a similar study by Nepali et al, who found otomycosis to be present in $4.7 \%$ in the study population.
Presence of foreign bodies, whether animate or inanimate in the auditory canal and nasal cavity is a common feature among the preschoolers and comparatively uncommon in the older age group. This is probably these children tend to insert objects due to boredom or curiosity. ${ }^{11}$

Foreign bodies, in the nose or the throat were one of the causes of emergencies in our hospital. This was more observed in younger children, below the age of 5 years. There were only 2 children in the school going age who had foreign particles in their throats, and that was also by accident. This was similar to a study by Sharma et $\mathrm{al}^{2}$ who also found the common age group to be 0-6 years while in a study by Kitcher et al, the common age group was found to be $0-9$ years. ${ }^{12}$

The most common foreign particles were small stones, vegetables and fruit particles, paper, chalk, mud particles etc. Similar cases were found in a study by Sharma et al. ${ }^{2}$ Coin was a common foreign body in some cases in other studies. $^{2,13}$

Among the nasal disorders, the most common was rhinitis which accounted for $55 \%$ of the overall cases and $60.7 \%$ of the nasal cases which was corroborated by other studies. ${ }^{2,10}$ Allergic rhinitis was seen to be associated with other conditions like asthma and other allergic conditions. $^{14}$

Local irritation in Kiesselbach's plexus leads to Epistaxis, which is relatively common in children. It could be due to local inflammatory diseases, infections and trauma. ${ }^{15}$ Most often, the bleeding is self limiting, but sometimes, it may be recurrent. In our study, we found to be $8.5 \%$. Yeli showed epistaxis prevalence of $15 \%^{8}$ while Sanjay et al showed the prevalence to be $16.6 \%$. $^{9}$

Among the throat disorders, pharyngitis was found most common followed by tonsillitis. The same was found in a study by Nepali et al whereas the prevalence of tonsillitis was more in a study by Yeli.

This study and its results are applicable to the geographical and socioeconomic status around our hospital. As we could not compare these results with another setup, we cannot ascertain the prevalence in other areas. As many patients do not always come to the hospital for ENT disorders and prefer to be treated over the counter or with alternate medicines, the morbidity could be much higher than predicted.

\section{CONCLUSION}

Our study suggests that Otitis media, pharyngitis, tonsillitis and rhinitis are the most common diseases of Ear, nose and Throat. Although many of the diseases are not much of a health concern, they are significant causes of pediatric morbidility. Therefore, this study provides the basic information of the prevalent disorders in ENT in 
our area, so that relevant development of the medical setup and treatment can be set up by the hospital.

Funding: No funding sources

Conflict of interest: None declared

Ethical approval: The study was approved by the Institutional Ethics Committee

\section{REFERENCES}

1. http://www.censusindia.gov.in/Census_Data_2001/I ndia_at_a_glance/broad.aspx.

2. Gul AA, Ali L, Rahim E, Ahmed S. Chronic suppurative otitis media; frequency of Pseudomonas aeruginosa in patients and its sensitivity to various antibiotics. Professional Med J. 2007;14:411-5.

3. Sharma K, Bhattacharjya D, Barman H, Goswami SC. Common Ear, Nose, and Throat Problems in Pediatric Age Group Presenting to the Emergency Clinic: Prevalence and Management: A HospitalBased Study: Indian Journal of Clinical Practice. 2014;24(8).

4. Logan Turner's Diseases of Nose, Throat and Ear, 10th edition. In: Maran AGD. New York: Elsevier 1988:464.

5. Sox CM, Finkelstein JA, Yin R, Kleinman K, Lieu TA. Trends in otitis media treatment failure and relapse. Pediatrics. 2008;121:674-79.

6. Finnbogadóttir AF, Petersen H, Laxdal $\mathrm{T}$, Gudbrandsson F, Gudnason T, Haraldsson A. Mastoiditis in children in Iceland. Laeknabladid. 2007;93:275-80.

7. Park's textbook of preventive and social medicine. In: K Park, editor. 18th ed. 2005:406.
8. Yeli S. Prevalence of ENT disorders among children in UAE: A tertiary medical care study. Int J Curr Microbiol App Sci. 2015;4(7):682-7.

9. Kishve SP, Kumar N, Kishve PS, Syed MMA, Kalakoti P. Ear Nose and Throat disorders in paediatric patients at a rural hospital in India. AMJ. 2010;3(12):786-90.

10. R Nepali, B Sigdel. Prevalence of ENT Diseases In Children: Hospital Based Study. The Internet Journal of Otorhinolaryngology. 2012;14(2).

11. Logan Turner's Diseases of Nose, Throat and Ear, 10th edition. In: Maran AGD. New York: Elsevier. 1988:464.

12. Kitcher ED, Janger A, Baidoo K. Emergency ear, nose and throat admission at Korle-Bu Teaching Hospital. Ghana Med J 2007;41(1):9-11.

13. Saha S, Chandra S, Mondal PK, Das S, Mishra S, Rashid MA. Emergency otorhinolaryngological cases in medical college, kolkata - a statistical analysis. Indian J Otolaryngol Head Neck Surg. 2005;57(3):219-25.

14. Pherwani A, Mankekar G, Chavan K. The study of co-morbid conditions in children with allergic rhinitis, from Mumbai, Maharashtra, India. Indian Journal of Otolaryngology and Head \& Neck Surgery. 2007;59(3):240-4.

15. Guarisco JL, Graham HD. Epistaxis in children: causes, diagnosis, and treatment. Ear Nose Throat J. 1989;68(7):522-32.

Cite this article as: Surapaneni H, Sisodia SS. Incidence of ear, nose and throat disorders in children: a study in a teaching hospital in Telangana. Int $\mathbf{J}$ Otorhinolaryngol Head Neck Surg 2016;2:26-9. 